\title{
Redo cases for mitral valve replacement on fibrillating heart - is the outcome better?
}

\author{
D Petkov ${ }^{*}$, V Papantchev, B Baev, G Nachev \\ From 23rd World Congress of the World Society of Cardio-Thoracic Surgeons \\ Split, Croatia. 12-15 September 2013
}

\section{Background}

Nowadays needs for redo cardiac surgery is more common. Number of patients requiring reoperation for significant mitral regurgitation is increasing. The aim of present work is to review our experience with redo cases for mitral valve replacement on fibrillating heart.

\section{Methods}

Between 2011 and 2013 a total number of 55 patients, 29 female and 26 male, with average age 62 years (from 42 to 75 ), underwent redo mitral surgery in our institution. Those were divided in two groups. Group 1 patients operated on fibrillation heart without aortic crossclamping (15 patients, average age 61 years, 4 female and 11 males) and Group 2 - patients operated with aortic cross-clamping and cardioplegic arrest (40 patients, average age 62 years, 25 female and 15 male). In all patients mitral valve replacement was performed. In 32 patients at least one more major cardiac procedure was also performed during the same surgery.

\section{Results}

In hospital mortality in group 1 was 2 patients (13\%) while in group 2 it was 8 patients (20\%). The CPB time was shorter in group 1 (average $95 \mathrm{~min}$ ) compared to group 2 (108 $\mathrm{min})$. Complications rate were as follows: heart failure -3 patients (20\%) in group 1 versus 15 patients (37.5\%) in group 2; acute renal failure - 1 patient (7\%) in group 1 versus 11 patients (27.5\%) in group 2; sepsis -2 patients (13\%) in group 1 versus 3 patients (7.5\%) in group 2; CNS complications -1 patients (7\%) in group 1 versus 1 patients (2.5\%) in group 2.

* Correspondence: petkovbg@yahoo.com

Department of Cardiac Surgery, 'St. Ekaterina' University Hospital, Sofia, Bulgaria

\section{() BioMed Central}

(c) 2013 Petkov et al; licensee BioMed Central Ltd. This is an Open Access article distributed under the terms of the Creative Commons Attribution License (http://creativecommons.org/licenses/by/2.0), which permits unrestricted use, distribution, and reproduction in any medium, provided the original work is properly cited.

\section{Conclusions}

Our experience shows that redo cases for mitral valve replacement on fibrillating heart have better outcome. The mortality and morbidity are reduces. We believe that the technique is easier and straightforward.

Published: 11 September 2013

doi:10.1186/1749-8090-8-S1-O281

Cite this article as: Petkov et al:: Redo cases for mitral valve

replacement on fibrillating heart - is the outcome better? Journal of Cardiothoracic Surgery 2013 8(Suppl 1):O281. and take full advantage of:

- Convenient online submission

- Thorough peer review

- No space constraints or color figure charges

- Immediate publication on acceptance

- Inclusion in PubMed, CAS, Scopus and Google Scholar

- Research which is freely available for redistribution 